\title{
Filosofia para crianças - avanços e desafios atuais: uma revisão sistemática de literatura
}

\author{
Philosophy for children - advances and current challenges: a \\ systematic literature review
}

Filosofía infantil - avances y retos actuales: revisión sistemática de la literatura

Mayara Faria de Souza ${ }^{1}$

\section{RESUMO}

O programa Filosofia para Crianças (FpC) é uma proposta educacional desenvolvida por Matthew Lipman e Ann Shapp (1990), a qual tem como finalidade principal desenvolver nas crianças a capacidade de pensarem por si mesmas. Nesse contexto, foi conduzida uma revisão sistemática de literatura com foco no âmbito do programa $\mathrm{FpC}$ no Ensino Fundamental anos iniciais, com o objetivo de descrever os principais avanços e desafios atuais nessa área. A busca compreendeu o período de 2018 a 2020, sendo que, de 153 artigos retornados, 26 estudos compuseram esta revisão. Os resultados revelaram que os principais avanços são a importância das comunidades de investigação, a relevância do trabalho com $\mathrm{FpC}$ ainda nos primeiros anos de escolarização e a necessidade de uma condução eficiente no processo de elaboração dos questionamentos para as sessões do programa FpC. Os desafios compreendem sobretudo a figura do professor, e os obstáculos enfrentados por eles na aplicação do programa FpC.

Palavras-chave: Filosofia para Crianças; Avanços; Desafios; Comunidades de investigação; Revisão sistemática.

\begin{abstract}
The Philosophy for Children ( $F p C$ ) program is an educational proposal developed by Matthew Lipman and Ann Shapp (1990), whose main purpose is to develop in children the ability to think for themselves. In this context, a systematic literature review was conducted with a focus on the FpC program in early elementary school, with the aim of describing the main advances and current challenges in this area. The search covered the period from 2018 to 2020, and, of 153 articles returned, 26 studies composed this review. The results revealed that the main advances are the importance of the research communities, the relevance of working with FpC even in the first years of schooling and the need for an efficient conduction in the process of elaborating questions for the FpC program sessions. The challenges mainly comprise the figure of the teacher, and the obstacles faced by them in the application of the FpC program.
\end{abstract}

Keywords: Philosophy for Children; Advances; Challenges; Communities of inquiry; Systematic review.

\section{RESUMEN}

El programa Philosophy for Children (FPC) es una propuesta educativa desarrollada por Matthew Lipman y Ann Shapp (1990), cuyo objetivo principal es desarrollar en los niños la capacidad de pensar por sí mismos. En este contexto, se realizó una revisión bibliográfica sistemática con enfoque en el programa FpC en la educación básica inicial, con el objetivo de describir los principales avances y desafíos actuales en esta área. La búsqueda cubrió el período de 2018 a 2020 y, de los 153 artículos devueltos, 26 estudios compusieron esta revisión. Los

\footnotetext{
${ }^{1}$ Mestranda no Programa de Pós-Graduação em Ensino de Ciências Humanas, Sociais e da Natureza da Universidade Federal do Paraná (UTFPR) e professora da rede municipal de Bandeirantes/PR - Brasil. E-mail: mayarafariasouza7@gmail.com.
} 
resultados revelaron que los principales avances son la importancia de las comunidades de investigación, la relevancia de trabajar con FpC incluso en los primeros años de escolaridad y la necesidad de una conducción eficiente en el proceso de elaboración de preguntas para las sesiones del programa FpC. Los desafíos comprenden principalmente la figura del docente, y los obstáculos que enfrenta en la aplicación del programa $F p C$.

Palabras clave: Filosofía para niños; Avances; Desafíos; Comunidades de investigación; Revisión sistemática.

\section{INTRODUÇÃO}

Nos últimos anos, muito se tem refletido sobre a verdadeira importância da Educação, sobre o desenvolvimento pretendido pelo seu intermédio e sobre o viés a ser adotado: mais conteudista, ou mais social e reflexivo para a formação do ser humano. A partir dessas discussões, comprovou-se a necessidade de aprimorar nos alunos o pensamento crítico, a ética e a moral, no intuito de formar crianças que se tornem cidadãos conscientes de seus deveres e responsabilidades.

Neste sentido, Matthew Lipman (1990) desenvolveu uma proposta educacional para o desenvolvimento dos campos cognitivo e do pensamento crítico ainda em crianças pequenas, visto que os estudantes chegavam nas universidades muito despreparados. Surgiu assim o programa Filosofia para Crianças (FpC), um método que tem por objetivo promover, ainda na infância, o pensamento, a linguagem e a reflexão crítica da sociedade, dado que, segundo seu proponente, quanto mais cedo for introduzida esta temática na vida infantil, maiores serão seus benefícios. Mesmo que a proposta tenha sido desenvolvida para crianças, pode envolver pessoas de qualquer idade, sendo praticável, dessa forma, tanto com crianças da mais tenra idade até com alunos da graduação e/ou profissionais já graduados, devido a seu potencial reflexivo e perceptivo. Os meios propostos por Lipman (1990) para alcançar esses objetivos são debates e reflexões, embora saliente que o principal método para a aplicação do programa $\mathrm{FpC}$ são as rodas de conversas, também chamadas de comunidade de investigação.

A comunidade de investigação se caracteriza como sessões em que se realizam discussões sobre temas variados, muitas vezes que chamam a atenção da comunidade a ser trabalhada. Nesta, livros, contos ou até mesmo filmes infantis podem ser utilizados como gatilho para o desenvolvimento de temas como bullying, moral, ética, meio ambiente, entre outros. Desse modo, a comunidade de investigação aprimora o debate, pois, além de serem realizadas as leituras dos conteúdos abordados, proporciona uma experiência para os participantes, ao permitir que aprendam a pensar e, de certa forma, a viver melhor.

Consequentemente, o programa $\mathrm{FpC}$ promove um ambiente seguro e a oportunidade das crianças de serem curiosas, bem como a capacidade e o direito de pensar por si mesmas, de pensar em comunidade, de discordar do pensamento dos outros ou com eles concordar, de mudar de opinião. Em suma, nas sessões do programa FpC, os estudantes estão livres para refletir e pensar da forma que lhes convém.

Diante do exposto, ao ponderar sobre a relevância do programa $\mathrm{FpC}$, esta investigação tem como objetivo apresentar uma revisão sistemática de literatura com foco no contexto do programa $\mathrm{FpC} \mathrm{no}$ Ensino Fundamental anos iniciais. O foco dado ao Ensino Fundamental anos iniciais deve-se sobretudo ao trabalho que a investigadora principal deste estudo exerce, como professora da Educação Básica nos ensinos Fundamental anos iniciais e Educação Infantil, dessa forma, optou-se por privilegiar 
trabalhos com alunos nessa faixa etária, no decorrer dos anos de 2018 a 2020, a fim de descrever os principais avanços e desafios da atualidade abordados nesta área.

Para isto, este artigo está organizado da seguinte maneira: a seção 2 detalha o programa de FpC, expondo sua origem, definições e objetivos; na seção 3 são apresentados alguns trabalhos relacionados, considerados relevantes no contexto da $\mathrm{FpC}$; na seção 4 é exposta a metodologia desenvolvida neste estudo; a seção 5 apresenta os resultados desta revisão sistemática; e por fim, na seção 6 são expostas as considerações finais deste estudo.

\section{FILOSOFIA PARA CRIANÇAS}

No final da década de 1960 o filosofo e educador norte-americano Mathew Lipman (1990), influenciado pelas ideias defendidas por Dewey (1859-1952), acreditava que alunos entre a Educação Infantil e o Ensino Médio deveriam ter aulas de Filosofia. Porque, considerava que a Filosofia possuía dentro de si tesouros pedagógicos de grande valia, "e que esses tesouros poderiam, algum dia seguir o método Socrático e dar sua valiosa contribuição para a educação (LIPMAN, 1990, p. 19).

Lipman (1990) ainda argumentava que é no início da educação escolar que a Filosofia pode ser melhor aproveitada, ao incentivar discussões disciplinadas e o aprimoramento do raciocínio, o qual é uma habilidade essencial para o desenvolvimento da leitura e da escrita. Nesse sentido, Matthew Lipman auxiliado por Ana Sharp, fundamentaram o programa curricular de Filosofia para Crianças, o qual segundo Cantalice e Cirino (2019, p. 66) tem como alicerce três objetivos complementares, "iniciação filosófica de crianças e jovens; educação para o pensar; e preparação para a cidadania responsável".

De acordo com Cantalice e Cirino (2019) o programa de FpC tornou-se um sistema educacional, que abrange diferentes princípios filosóficos-educacionais, metodológicos e práticos, ao abranger crianças desde a Educação Infantil até o Ensino Médio, e também ao sistematizar um currículo em livros denominados de novelas filosóficas. Essas novelas, conforme as autoras, procuram tratar de assuntos do cotidiano de crianças de diferentes idades, para assim discuti-los em sala de aula. Dessa forma, o programa de $\mathrm{FpC}$ é uma proposta educacional cujo objetivo é o desenvolvimento do pensamento e do raciocínio dos alunos, por meio das discussões filosóficas em sala de aula, para que assim estes alunos aprendam a pensar por si mesmos.

Pensar por si mesmo requer dar mais atenção aos interesses e pontos de vista das crianças, que é um pré-requisito para apresenta-Ihes a filosofia de uma forma mais atraente [...]. Filosofia para Crianças não pressupõe que pensar por si mesmo, por se tratar de um pensamento aplicado de forma relevante, deva ser mais importante do que enfatizar as crianças a adquirirem outros tipos de habilidade de raciocínio mais gerais. Mas, certamente, no caso das crianças, não exige, em absoluto, uma ênfase maior (LIPMAN et. al, 2001, p. 69).

Nesse sentido, quando as crianças são estimuladas a pensarem filosoficamente e a refletir, a sala de aula transforma-se em uma comunidade de investigação, a qual segundo Lipman et. al (2001) apresenta um comprometimento com os procedimentos da investigação, com a procura de técnicas que presumem uma abertura a evidência e a razão. Quando são internalizados esses procedimentos da comunidade, transformam-se em hábitos de reflexão.

Uma vez que, uma das premissas do programa de FpC é a participação efetiva das crianças nos diálogos e discussões realizadas em sala de aula, as crianças passam a ter um papel ativo, em seu 
processo de ensino aprendizagem, e os professores devem reconhecer que seus alunos podem "advir, e advêm de fato, válidos contributos para o pensamento da comunidade, para a filosofia enquanto património da humanidade, as crianças não devem ser apenas vistas, mas vistas e, sobretudo, ouvidas" (CARVALHO, 2020, p. 37).

Desse modo, de acordo com Moreno e Marta (2018), a aplicação do programa FpC nas escolas permite torná-la uma ferramenta conceitual, metodológica e experimental a serviço do conhecimento e da formação humana. O programa $\mathrm{FpC}$ busca estimular nos alunos à construção de suas próprias ideias, argumentos e conclusões, por meio de técnicas de investigação no estilo de Sócrates. Ao ensinar a filosofia desde os primeiros anos da infância, poderá ser formado um pensador, um pesquisador e um transformador criativo da realidade em que se vive, segundo os autores.

Conforme Michalik (2019), o programa FpC tem um potencial de ajudar o ensino, a aprendizagem, a educação e o desenvolvimento escolar a tornarem-se experiências coletivas dialógicas, participativas e democráticas. Os estudos realizados pelo autor demonstram que tanto os professores quanto os alunos alcançam um desenvolvimento significativo ao fazerem parte de sessões regulares de filosofia. Nesses estudos, os professores relatam como as sessões de filosofia os ajudaram a transformar suas ideias sobre o ensino e sobre como lidam com seus alunos, o que afetou o progresso pessoal e profissional, visto que houve grande alcance de implicações para a compreensão de si mesmos como educadores e para sua prática pedagógica.

Com relação às crianças, além do conteúdo da discussão filosófica, outros fatores relevantes são: o processo de pensar juntas e a troca de ideias, que podem permitir examinar e expandir sua própria posição, em razão de que as discussões em grupos promovidas são ilustrações impressionantes da vontade e da capacidade da criança em envolver-se com a reflexão coletiva. Além disso, a observação das variedades de opiniões e perspectivas permite que a incerteza em relação aos resultados da investigação e da pesquisa filosófica seja vista como uma experiência positiva, além de um desafio ao desenvolvimento do próprio pensamento, possibilitando, assim, chegar ao objetivo de refletir mais (MICHALIK, 2019).

A comunidade de investigação é uma das formas de aplicação do programa de FpC mais utilizadas, conforme defende Canuto (2018). Segundo o autor, o diálogo filosófico em uma comunidade de investigação aprimora as habilidades de pensamento crítico das crianças e permite que elas pensem de maneira reflexiva, façam perguntas e julgamentos razoáveis. Ademais, verifica-se que as crianças apresentem um avanço no uso de suas habilidades de raciocínio intuitivo, principalmente quando corrigem suas noções iniciais de algum conceito no momento em que seus colegas apresentam argumentos mais fortes ou quando apontam pontos fracos em suas declarações.

Em síntese, o programa de $\mathrm{FpC}$ pode ser considerado uma proposta educacional, que tem por finalidade o desenvolvimento do pensamento e do raciocínio em alunos pequenos. Sua aplicação pode ser iniciada ainda na Educação Infantil, por meio de atividades que promovam o diálogo, a reflexão e o pensar junto, os quais são proporcionados pelas comunidades de investigação. 


\section{TRABALHOS RELACIONADOS}

Muitos estudos sobre a temática do programa $\mathrm{FpC}$ não realizam aplicações a um público-alvo e trazem suas contribuições no formato de pesquisas sobre o estado da arte - assim como o desenvolvido neste trabalho. Tais estudos discutem a relevância desse programa pedagógico utilizando-se de metodologia voltada para uma abordagem de revisão bibliográfica, a exemplo do que fazem autores como Kilby (2019), Rodriguez (2018), Mendonça e Carvalho (2019).

No trabalho de Kilby (2019), o autor desenvolve uma revisão bibliográfica com o objetivo de explorar, por meio da análise de crenças e valores, como as perspectivas de professores(as) acrescentam valor significativo na educação. Como resultado, o autor confirma que o programa de FpC é, de fato, influenciado por esses fatores, uma vez que as percepções e as compreensões desses profissionais desempenham um papel vital na implementação de qualquer mudança educacional. 0 texto expõe ainda que, ao cogitar-se a implementação do programa $\mathrm{FpC}$ nas escolas, é necessário que sejam garantidas aos professores as conexões com os métodos e com as práticas suficientes para assegurar sua adequada execução.

O pesquisador Rodriguez (2018) realiza uma investigação que teve como intuito descrever o programa FpC holisticamente e, em particular, no detalhamento de sua dimensão ética, a fim de discutir como esta pode configurar-se como um programa de educação moral. No decorrer da pesquisa, o autor constata que a proposta pedagógica elaborada por Matthew Lipman pode constituir um programa de educação moral, visto que os elementos da proposta do programa FpC são voltados para tal compreensão, ou seja, a metodologia é concebida para propiciar tal configuração, especialmente por possibilitar o diálogo. Dessa forma, o autor conclui que o programa FpC contempla uma abordagem holística que procura entender integralmente a pessoa e tende a quebrar dicotomias, principalmente as afetivo cognitivas, bem como ressalta a necessidade de vincular o pensamento à ação na educação moral, bem como a importância da narração como elemento fundamental no desenvolvimento da moralidade.

Por fim, a revisão realizada pelas autoras Mendonça e Carvalho (2019) tem como propósito defender que as variadas abordagens dentro do programa $\mathrm{FpC}$ poderiam ser aprimoradas se integrassem, de forma intencional, a exploração do questionamento, no lugar de apenas apresentar às crianças perguntas já preparadas como pontos de partida da investigação. Neste sentido, destaca-se como principal colaboração da pesquisa a constatação de que as perguntas nas comunidades de investigação são muito importantes, embora, para a excelência da investigação e aplicação do programa $\mathrm{FpC}$, o foco deva ser a formação do grupo para discuti-las.

Em consequência do discutido na presente seção, cabe ressaltar que a relevância do trabalho aqui proposto encontra-se no fato de que, na pesquisa empreendida para sua realização, não foi encontrada nenhuma publicação que adotasse, como metodologia de desenvolvimento, uma revisão sistemática de literatura. Percebeu-se, dessa forma, que tanto mapeamentos como revisões sistemáticas de literatura com foco no programa $\mathrm{FpC}$ não são numerosos, e investigações nesse campo podem representar uma contribuição para pesquisadores que tenham interesse nesta área de estudo. 


\section{METODOLOGIA}

Para realização deste trabalho, optou-se por utilizar o método de revisão sistemática de literatura, pois minimiza o enviesamento da escolha bibliográfica, na medida em que é realizada uma busca dos textos publicados sobre o tema em questão sem levar em conta análises prévias (DENYER; TRANFIELD, 2009). Ramos, Faria \& Faria (2014) indicam que o propósito de uma revisão sistemática é resumir a melhor pesquisa disponível acerca de uma questão específica, o que é feito por meio da síntese dos resultados de diversos estudos.

Para a condução desta revisão, utilizou-se como referência Ramos, Faria \& Faria (2014), a escolha desse estudo como suporte para realização desta pesquisa se justifica devido a tais autores explicarem de forma direta e clara como realizar uma revisão sistemática de literatura em Ciências da Educação, salientado atributos para a inovação e investigação nesta área, a qual este estudo pertence. Nesse sentido, esta pesquisa utilizou como método para conduzir revisões sistemáticas, o seguinte protocolo: (1) definir os objetivos; (2) definir as strings de busca; (3) definir bases de dados; (4) definir critérios de inclusão; (5) definir critérios de exclusão; (6) definir critérios de validade metodológica; (7) tabular os dados e (8) realizar tratamento de dados. De acordo com Ramos, Faria \& Faria (2014), é imprescindível que sejam registradas todas as etapas da pesquisa, não apenas para que essa seja replicável por outro investigador, como também para registrar-se que o processo em curso segue uma série de etapas previamente definidas e respeitadas. Os autores propõem, neste domínio, que se implementem os passos do protocolo ilustrado na Figura 1.

Figura 1: Etapas do Processo de Revisão Sistemática de Literatura.

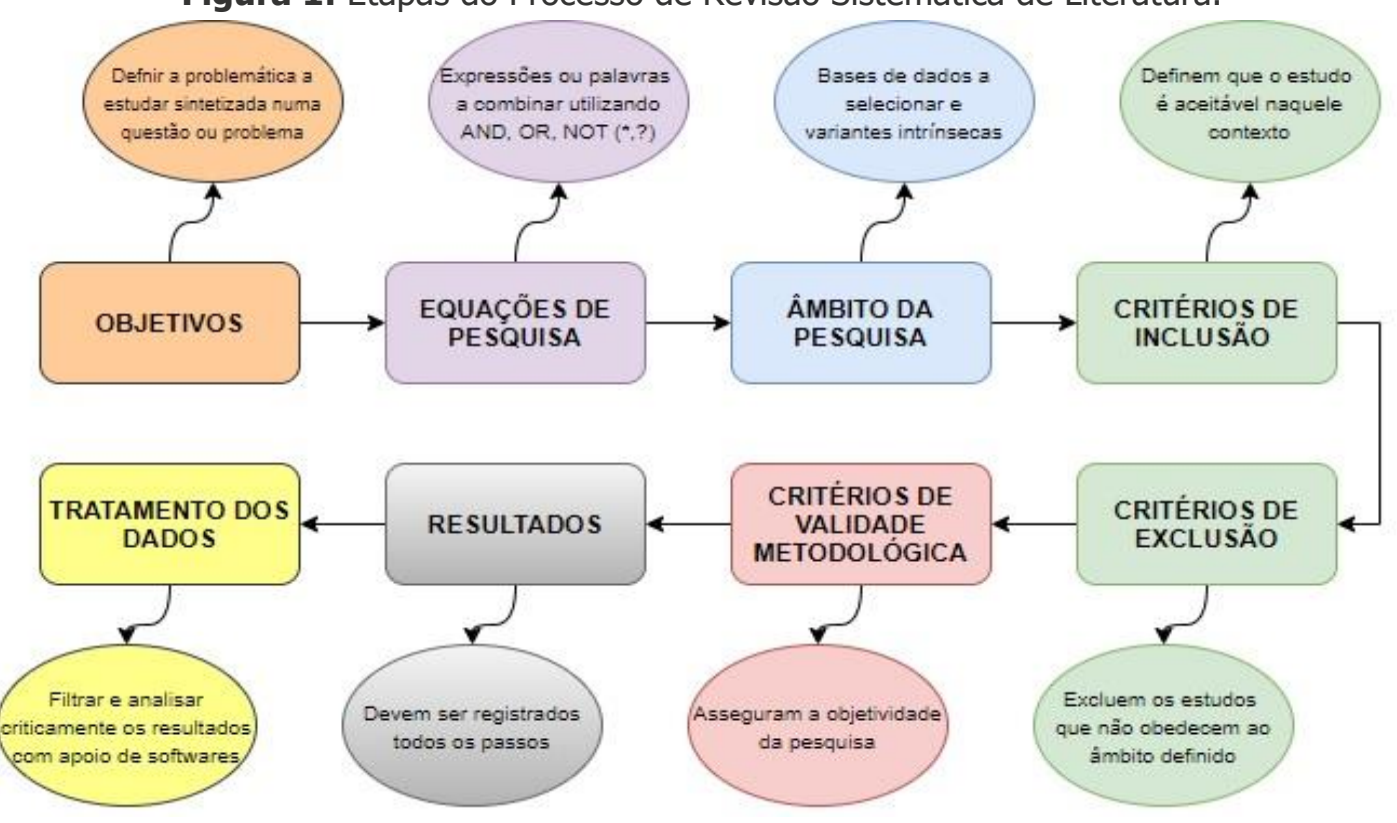

Fonte: Adaptado de Ramos, Faria \& Faria (2014).

Como pode ser verificado na Figura 1, o primeiro passo do processo é a definição dos objetivos da investigação, que, nesta revisão, são responder a duas questões de pesquisa:

- QP1: Quais as principais oportunidade de estudo identificadas nos trabalhos analisados?

- QP2: Quais os principais desafios relatados nestes estudos?

Com relação à string de busca, optou-se por utilizar um termo genérico: "philosophy for children" and "elementary education", a fim de alcançar um amplo conjunto de estudos. 
O âmbito da pesquisa, que corresponde às bases de dados nas quais os artigos foram buscados, foi constituído, no presente estudo, pela base Redalyc. Foi utilizada somente esta base pois, em primeiro lugar, essa trouxe artigos bastante relevantes e em número considerável. Em segundo lugar, a digitação da string em outras bases de dados não obteve sucesso, dado que, na SciELO, nenhum artigo foi retornado; na ERIC, apenas um artigo dentro do período de interesse foi retornado - 0 qual, contudo, não atendia a temática abordada -; e, nos periódicos da CAPES, somente dois artigos foram encontrados, em meio a dezenas retornados que contemplavam algumas características desejadas para esta revisão, mas que foram por fim excluídos por não se adequarem ao período nem à temática pretendida.

Além disso, a base de dados Redalyc indexa os artigos da revista Childhood \& Philosophy, que aborda publicações que contemplam justamente a temática central deste estudo. Por esses motivos, optouse por manter somente a base Redalyc para a presente revisão sistemática, que possuía um foco maior na qualidade dos estudos selecionados, e não na quantidade de estudos analisados que geralmente são o foco de mapeamentos sistemáticos. Como este artigo é revisão de literatura e não de mapeamento, que busca uma ampla gama de artigos, a pesquisa foi limitada para que fosse possível expor todos os resultados alcançados, de forma a lista-los e não apenas mostrar de forma quantitativa os dados relacionados as publicações, dessa forma esta restrição foi intencional. Ao passo que também, se destaca que a maioria dos artigos encontrados da área pesquisada estão em língua inglesa, por isso adotou-se essa língua como preferencial.

Quanto aos critérios de inclusão e exclusão, foram assim definidos: 1) Critérios de Inclusão - (a) artigos em Português, Inglês ou Espanhol; (b) artigos completos ou resumos; (c) artigos que contemplassem a temática Filosofia para crianças no Ensino Fundamental anos iniciais; (d) artigos publicados entre 2018 e 2020 - a pertinência das datas, são relevantes para o desenvolvimento do mestrado da investigadora principal deste estudo, que busca entender o contexto atual do ensino do programa Filosofia para Crianças. 2) Critérios de exclusão - (a) artigos duplicados; (b) que não estivessem nas línguas definidas nos critérios de inclusão; (c) ensino de filosofia que não fosse para crianças; e (d) estudos que não estivessem no âmbito do Ensino Fundamental anos iniciais.

O sexto passo, relativo aos critérios de validade metodológica, devem assegurar a replicação do processo. Para este trabalho, todos os artigos retornados da busca passaram por dois níveis de triagem: (1) os resumos de todos os artigos retornados na busca foram lidos pelos autores, dos quais foram selecionados aqueles que atendessem aos critérios de inclusão mencionados; (2) na sequência, com o intuito de verificar se as pesquisas selecionadas realmente satisfaziam os critérios de inclusão ou deveriam ser descartados por atender a algum critério de exclusão, a primeira autora realizou a leitura dos artigos, enfocando a metodologia utilizada pelos autores, resultados alcançados e conclusões. A leitura da revisão bibliográfica e da introdução foi feita de forma rápida, sendo conduzida leitura mais apurada apenas se alguma informação não fosse compreendida nos demais itens.

No tocante à Tabulação e ao Tratamento dos dados, o mapeamento foi conduzido com o apoio das ferramentas Parsifal ${ }^{2}$ e Excel. Os dados foram analisados em uma dimensão quantitativa - apenas para contagem de ocorrência para elaboração de estatísticas descritivas - e qualitativa categorização, para exposição dos pontos principais de cada estudo selecionado. O detalhamento da condução do mapeamento, baseado no protocolo proposto por Ramos, Faria \& Faria (2014), pode

\footnotetext{
2 https://parsif.al/
} 
ser observado na Figura 2, na qual são apresentados todos os passos metodológicos realizados, desde a definição dos objetivos até o tratamento dos dados, com o propósito de obter resultados baseados nas três questões de pesquisa formuladas. Na seção 5 , os resultados são apresentados e essas questões são respondidas.

Figura 2: Detalhamento da Condução da Revisão.

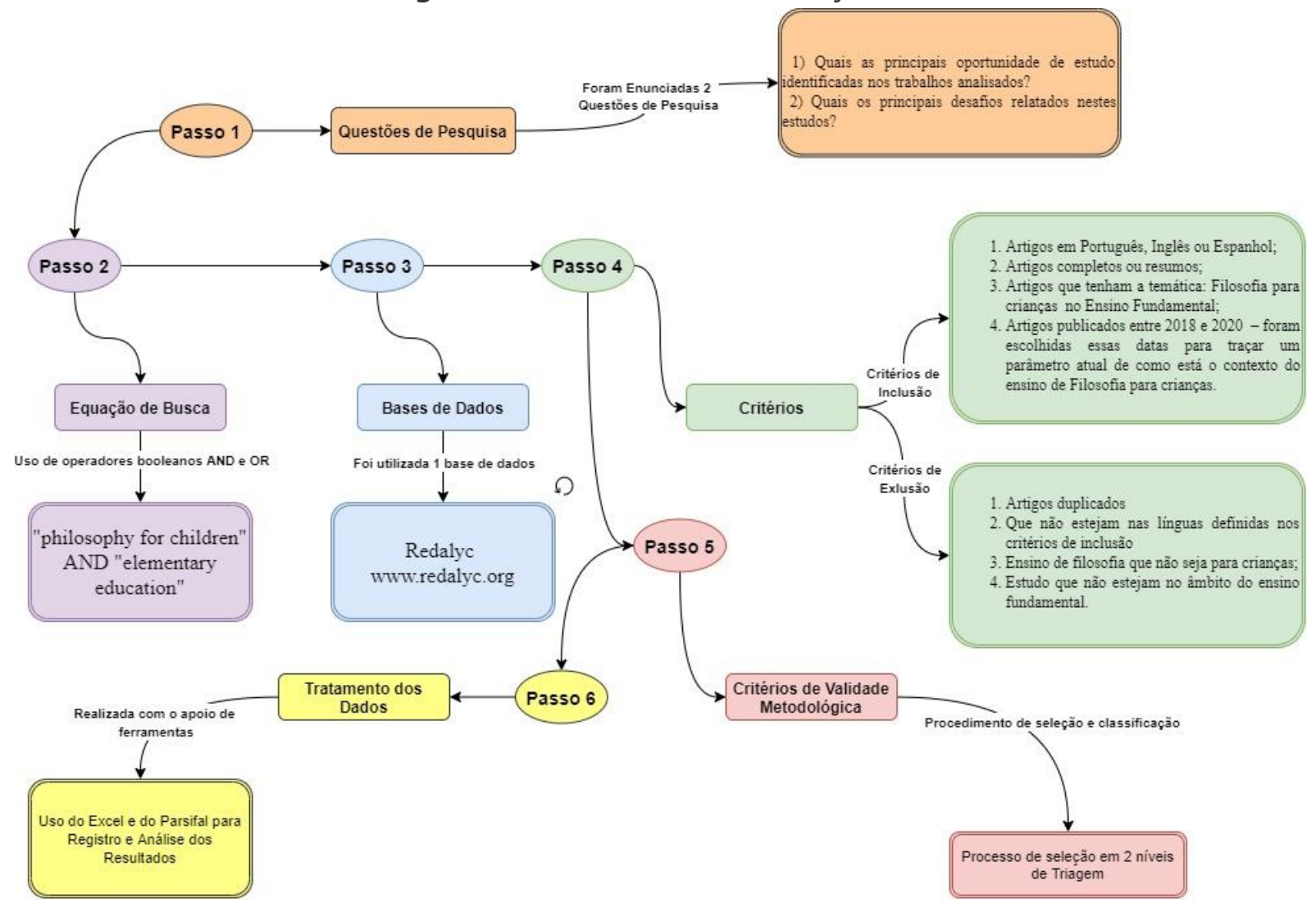

Fonte: Autora (2020)

\section{RESULTADOS}

Ao desenvolver a investigação na base de pesquisa Redalyc, retornaram 153 artigos, dos quais todos os resumos e elementos essenciais estão disponíveis no link que consta no rodapé ${ }^{3}$. Cabe ressaltar que, dentre esses, 118 artigos foram excluídos, por tratarem de assuntos que não estavam de acordo com a temática proposta, a Filosofia para Crianças. Outras seis publicações foram excluídas porque, apesar de abordarem a Filosofia para Crianças, não o faziam no âmbito do Ensino Fundamental anos iniciais, o que também fugia da proposta aqui elaborada. Além disso, dois textos foram excluídos devido ao idioma em que foram escritos, e um texto foi excluído por tratar-se da apresentação de um dossiê com somente os resumos de diversos artigos. Dessa forma, no decorrer do processo de triagem para essa revisão sistemática de literatura, foram excluídos 127 artigos, restando 26 investigações, que foram lidas e analisadas. Todos os elementos essenciais dos artigos incluídos nesta revisão estão disponíveis no link que consta no rodapé ${ }^{4}$.

Nesse sentido, para o estabelecimento dos 26 artigos selecionados, o periódico que mais retornou publicações foi o Childhood \& Philosophy, embora tenham sido igualmente selecionadas publicações

${ }^{3}$ Link para acesso aos artigos retornados na revisão.

${ }^{4}$ Link para acesso aos artigos que compuseram essa revisão. 
dos periódicos Ciencia y Sociedad e Innovación Educativa (México, DF). O ano de maior concentração de publicações selecionadas foi 2019, uma vez que, até o dia 30 de abril de 2020, data em que se deu a seleção dos artigos, não havia publicações nessa temática em 2020. A síntese dos artigos que compõem esta revisão sistemática, com os objetivos e os principais resultados, de cada um dos 26 estudos, é detalhada na subseção seguinte.

\subsection{Síntese dos Resultados e Discussões}

O estudo realizado por Albert (2018), tem como objetivo estabelecer uma relação entre abordagem moderna da infância e educação libertadora, a qual estimula que as crianças desempenhem um papel mais ativo nas escolas. Como principal resultado o autor apresentou a descrição de uma proposta de como afastar-se das formas tradicionais e perceber a infância em direção a uma abordagem moderna, no lugar de ver a infância como um estágio da vida, a concebe como um processo de amadurecimento. Esse texto, é relevante pois discute a necessidade de colocar os alunos como o centro de todo processo pedagógico, o que se diferencia das abordagens tradicionais infelizmente ainda utilizadas na educação nacional

O objetivo da pesquisa desenvolvida por Papathanasiou (2019) foi provocar perguntas filosóficas nos pais, como praticado com as crianças. Como resultado, apresentou como a escola integrou os pais nas atividades educativas dos filhos, como os pais procuraram cooperar mais com as atividades escolas e extraescolares dos filhos. Em seguida analisou-se o trabalho de Newby e Gardner (2019), os autores tiveram como intuito avaliar a articulação das falhas de um modelo hierárquico, que o modelo não hierárquico pode (e deve) corrigir. O resultado apresentado demonstra a responsabilidade do facilitador de trazer estratégias para solicitar respostas pessoais dos jovens envolvidos e denota que, ao adotar-se uma estratégia não hierárquica, essa por si só não será superior a abordagem tradicional.

Reynolds (2019) teve como objetivo investigar como o processo de fazer o círculo pode contribuir para a construção da comunidade de investigação. Alcançou como resultado, a percepção da importância do "sentar-se junto em círculo" e mostrou como isso possibilita a democratização do conhecimento e a contestação da dinâmica do poder, além de salientar a ideia de pensar junto. 0 texto apresentou, uma perspectiva interessante sobre as comunidades de investigação, local que de acordo com Lipman et. al (2001), de preferência todos devem se sentar na mesma posição sem diferenciação, principalmente o professor, a fim de instituir uma coprodução de conhecimento e de reflexão. Na sequência foi analisado o manuscrito de Kilby (2019), que tinha como finalidade, entender a importância das crenças e valores dos professores(as), especialmente no contexto FpC. O autor obteve como resultado, a ampliação da compreensão de como a prática da FpC é influenciada pelas crenças e valores dos professores.

Em seu trabalho Canuto (2018), contou com o seguinte objetivo, investigar a eficácia da Filosofia para Crianças (FpC). Apresentou como conclusão, que as habilidades do pensamento crítico das crianças progrediram nas quinze sessões de $\mathrm{FpC}$, bem como houve o desenvolvimento da qualidade do pensamento crítico, assim como as habilidades de raciocínio. Essa colocação do texto, faz referência ao objetivo geral de todo trabalho realizado por Lipman et. al. (2001), ao criar o programa de $\mathrm{FpC}$, o qual era propiciar que as crianças desenvolvessem o raciocínio e o pensamento, o que pode ser realizado por meio dos diálogos e discussões, das comunidades de investigação. Hawken (2019) estabeleceu como intuito para seu trabalho, definir a natureza e as características da mente 
aberta, analisar sua emergência nas discussões filosóficas e, além disso, estudar seu papel na prática da filosofia. Como principal resultado apresentou que, por meio da técnica de mente aberta, as crianças desenvolveram: a capacidade de complementar ideias, de pensar coletivamente, de reformular, explicar as ideias dos outros.

No estudo desenvolvido por Santi (2019), o objetivo proposto era, analisar de forma crítica o conceito de competência, observado através das lentes da abordagem das capacidades. O qual, obteve como conclusão, a comprovação da incapacidade de testes como o PISA, em medir o conhecimento dos alunos, devido a impossibilidade de medir o incomensurável. No trabalho realizado por Alt (2019) a finalidade era compreender os feitos da FpC com relação a seu desenvolvimento linguístico e atos discursivos. Como resultado, descreveu como um grupo de crianças que praticaram o filosofar, apresentaram melhora no desenvolvimento das habilidades de comunicação e no uso de conectores de frases. O exposto por esse estudo, pode ser encontrado em diferentes trabalhos sobre a temática, sobretudo porque a aplicação da prática de comunidade de investigação do programa de $\mathrm{FpC}$, pode desenvolver e melhorar a fala das crianças, por meio dos diálogos e reflexões propostos em salas (KAŹMIERCZAK, 2020).

A proposta elaborada por Elicor (2019), teve como propósito integrar formas de conhecimentos indígenas na teoria e prática da FpC. Como conclusão, o autor mostrou que alguns padrões epistemológicos indígenas tendem a criar um espaço conceitual e prático que permite uma possível integração de formas de conhecimento indígenas dentro das premissas da FpC. Rodriguez (2018) produziram um artigo com o intuito de apresentar uma proposta de $\mathrm{FpC}$ pensada holisticamente, em particular, em sua dimensão ética, por meio de um programa de educação moral. Obtiveram como conclusão, a confirmação da expressa relevância do diálogo filosófico, como o apresentado na FpC, ao educar o sujeito moral, bem como a necessidade de vincular o pensamento a educação moral.

Na sequência foi analisada a pesquisa de Moreno e Marta (2018), que tinha como finalidade destacar a importância e os benefícios do programa de $\mathrm{FpC}$, por meio da apresentação dos romances que constituem o suporte que compõe o programa, o papel do professor e o método comunitário de investigação. Como principal resultado, evidenciaram que com a aplicação do programa FpC na escola, a filosofia torna-se uma ferramenta conceitual, metodológica e experiencial, a serviço do conhecimento humano e, consequentemente da formação humana. Nesse sentido, o referido texto procurou demonstrar as vantagens da aplicação do programa, abordando como as crianças se estabelecem de forma ativa em seus processos de ensino e de aprendizagem.

Shapiro (2019) tinha como objetivo rever em que sentido a deliberação na comunidade de investigação é filosófica. Concluiu, que a seleção recortada e o histórico curricular que a FpC faz com a filosofia deixa-a delineada como uma mera ferramenta, como um corpus que apenas assume valor na medida em que pode contribuir para esses objetivos sócio-políticos. Entretanto, em nenhum momento ao elaborar o programa FpC, Lipman et. al (2001) teve a intenção de tornar as criança pequenos filósofos, tinha como intuído na verdade, que as crianças tivessem um espaço para poderem refletir em conjunto, no qual poderiam expor suas ideias e falas, com isso ampliarem o desenvolvimento dos seus pensamentos.

O estudo desenvolvido por Daniel (2018), apresentou como intuito principal elaborar uma ferramenta de avaliação rigorosa e significativa, que contribuiria para avaliação e a compreensão dos processos cognitivos das crianças que se beneficiam das práxis filosóficas. Como resultado, entregou um modelo do pensamento crítico dialógico, que emergiu da análise, por meio da teoria fundamentada, que 
representa uma ferramenta valiosa para professores que desejam avaliar o progresso de aprendizagem de seus alunos consolidando ou aprimorando sua facilitação filosófica. Em seguida pode-se explorar o estudo elaborado por Moriyón (2019), que possuía como escopo aprofundar algumas questões fundamentais da proposta educacional de $\mathrm{FpC}$. O autor chegou a conclusão, que as propostas de Sharp e Lipman são regulatórias ou normativas, o esforço deve ser direcionado para um ideal que transcende o mundo como ele é, e o projeta no mundo como deveria ser.

O artigo elaborado por Splitter (2019), contou com objetivo de explorar as confusões conceituais acerca da natureza da identidade, a dicotomia coletivista/individualista; o declínio dos canis midiáticos legítimos e sua substituição palas mídias sociais; e o fracasso dos eleitores em sustentar suas responsabilidades como cidadãos de uma democracia. Expôs como implicações de seu estudo que quando as crianças tem acesso a $\mathrm{FpC}$ desde cedo e participam das comunidades de investigação, elas têm a oportunidade de uma educação democrática, portanto desenvolvem um raciocínio crítico poderoso, o qual dificulta a propagação de pensamentos populistas e do tribalismo.

Postiglione (2018) tinha como finalidade compreender o processo de escolha de perguntas para as comunidades de investigação. Chegou à conclusão, que a proposta das comunidades de investigação se dedica a garantir tanto a natureza epistêmica do diálogo, quanto a inclusão real de todos os participantes durante o processo de escolha das perguntas, que é uma forma de todos os membros participarem. Nessa perspectiva, as perguntas para o programa de $\mathrm{FpC}$ e para as comunidades de investigação são primordiais, pois é por meio delas que as crianças refletem e constroem seus próprios entendimentos, segundo Carvalho (2020, p. 159) "na filosofia o objetivo não é apresentar soluções feitas para entregar às crianças num modelo já pronto a consumir. Pelo contrário, a filosofia acolhe e celebra as inquietudes que fervilham nas perguntas".

Michalik (2019) tinha como objetivo explorar as experiências de professores e crianças com a FpC, por meio da análise do conteúdo de entrevistas realizadas com professores e alunos. Como resultado, descreveu como as sessões regulares de filosofia podem contribuir para professores terem uma compreensão maior de si mesmos como educadores. Já para as crianças, o fator principal é o processo de pensar as coisas em conjunto, a maneira como a troca de ideias lhes permite examinar e expandir sua própria posição. O artigo elaborado por Walczak (2019), contou com o seguinte intuito: criticar a teoria piagetiana do desenvolvimento intelectual elaborada por Gareth B. Matthews (1929-2011). Como resultado, apontou como a filosofia pode ser considerada algo periférico ao desenvolvimento cognitivo, independente de todas as maneiras pelas quais esse processo pode ser entendido e explicado.

Mariscal (2018), em seu texto aborda como realizar estudos sobre as relações entre educação, paz e críticas inclusivas, estabelecendo-as como os principais elementos para a realização dos objetivos de uma escola pluralista. Como principal resultado, apresentou como a $\mathrm{FpC}$, enquanto programa, se concentra precisamente no intercambio do dialógico e pode ser um bom aliado para 0 desenvolvimento da cultura da paz. O texto faz referência a perspectiva da FpC ser promotora da igualdade de participação, bem como da escuta significativa do outro, pautada no respeito mútuo, promovido nas comunidades de investigação. Em seguida com a leitura do manuscrito de Nishivama (2019), observou-se que seu intuito era desenvolver um conceito estrito ou universal de consenso. Nas suas conclusões o autor salienta que a realização do meta-consenso seria benéfico para facilitar o processo filosófico de uma maneira diferente, não unindo visões diferentes em uma única caixa, 
mas respeitando essas diferenças, retratou também a ideia de que o meta-consenso oferece o insight sobre como pode-se avaliar a qualidade da investigação filosófica.

Ao elaborar seu texto, as autoras Mendonça e Carvalho (2019), especificaram como objetivo defender que as variadas abordagens dentro da $\mathrm{FpC}$, ganharam em integrar de forma intencional, a exploração do questionamento. Como conclusão, destacaram a importância da forma como as perguntas são formuladas nas comunidades de investigação, entretanto reconhecem que mais importante do que as perguntas, é o grupo formado para discuti-las. Como mencionado acima, as perguntas são fundamentais para o programa de $\mathrm{FpC}$, mas o processo para sua realização, do mesmo modo que a comunidade é formada, são fundamentais para o processo de reflexão e aprimoramento do pensamento infantil.

Charabati (2019) realizou uma experiência com a FpC, a partir de uma obra clássica, o Peter Pan. A obra foi exposta aos alunos da educação infantil com os seguintes intuitos: a) desenvolver o pensamento crítico; b) desenvolver habilidades de análise; c) relacionar suas experiências cotidianas com as situações que surgem na história. Como resultado, o autor apontou como as obras literárias podem servir de gatilho para a reflexão e o debate, os alunos conseguiram apropriar-se das perguntas colocadas no contexto da obra e respondê-las com base em suas experiências pessoais. Essa metodologia colocada pelo autor, de utilizar histórias já conhecidas das crianças, para trabalhar assuntos filosóficos nas comunidades de investigação, foi proposta por Murris (2016). A autora argumenta que com crianças da Educação Infantil, o trabalho filosófico pode ser mais fácil, se for realizado por meio de histórias infantis já conhecidas das crianças.

O trabalho desenvolvido por Aslanimehr et al. (2018), contou com o seguinte objetivo: investigar como desde uma idade tenra, as crianças formam uma relação com a natureza, e o efeito que a natureza pode ter nas relações das crianças consigo mesmas, com os outros e com seus ambientes. Como resultado, evidenciaram que similarmente a maneira como os filósofos refletem sobre o conceito de natureza, também as crianças engajadas com a complexidade e a abertura do conceito de natureza na comunidade de investigação, podem desenvolver essa forma de pensar.

Encerrando as análises dos artigos selecionados, Barrientos (2019) elaborou uma pesquisa com o objetivo de descrever as limitações da abordagem cognitiva do trabalho filosófico. Concluiu que, ao apresentar uma proposta de intervenção, por meio do programa de $\mathrm{FpC}$, é necessário ter o foco na experiência dos alunos, e depois, em sua reflexão. Entretanto, uma das concepções do programa de $\mathrm{FpC}$, é proporcionar que os alunos pensem sobre suas realidades, a reflexão deve ser realizada em conjunto, a partir de suas próprias experiências, pois não haveria como acontecer uma educação democrática, a qual é pregada por Lipman et. al (2001), sem que a realidade dos alunos façam parte da sala de aula, ou das comunidades de investigação. Por fim, analisou-se o estudo realizado por Worley e Worley (2019), os autores tiveram como propósito comparar o impacto do ensino explicito de habilidades de pensamento crítico durante uma pesquisa, apenas com o método de investigação filosófico da The Philosophy Foundation. Como resultado principal, apresentaram o desenvolvimento de um experimento, que resultou na seguinte constatação, que é possível dizer que a $\mathrm{FpC}$ ajuda a desenvolver habilidades metacognitivas.

Desta maneira, com base nos resultados sintetizados nesta seção e na apropriação e reflexão sobre o conteúdo, bem como sobre os resultados de cada estudo pesquisado, foi possível responder às questões de pesquisa apresentadas na seção Metodologia, que compuseram o intuito desse estudo. Tais repostas são apresentadas nas subseções seguintes. 


\subsection{QP1 - Quais as principais oportunidades de estudo identificadas nos trabalhos analisados?}

Primeiramente, para responder a esse questionamento, foi preciso analisar todos os artigos pesquisados, com o objetivo de identificar as principais oportunidades manifestadas pelos autores no desenvolvimento de seus estudos na área do programa de $\mathrm{FpC}$ no âmbito do Ensino Fundamental anos iniciais. Nessa perspectiva, é importante evidenciar as investigações de Hawken (2019), Moreno e Marta (2018) e Mendonça e Carvalho (2019).

Umas das principais oportunidades de pesquisa identificadas foi no estudo desenvolvido por Hawken (2019) partiu da observação de que, por meio das comunidades de investigação, as crianças adquirem a capacidade de pensar coletivamente, uma vez que o pensamento é conquistado a partir do momento que o sujeito interage com outros sujeitos. Dessa forma, as discussões filosóficas entre crianças, enquanto lugares de mente aberta, de pensamento colaborativo, de ajuda mútua, são por si próprias práticas cívicas e éticas. A interação promovida por tais encontros desenvolve uma empatia intelectual e faz com que as crianças trabalhem em conjunto para adquirirem a capacidade de pensar e refletir, de modo que cada membro da comunidade enriqueça o processo de raciocínio do outro.

Do mesmo modo, Moreno e Marta (2018) desenvolveram uma investigação que identificou a importância de ensinar a filosofia desde os primeiros anos da infância, oportunizando a formação de um pensador, um pesquisador, pois, ao filosofar, é preservada nas crianças a curiosidade sobre tudo e a capacidade de não tomar nada como garantido. Outra razão para ensinar filosofia para crianças pequenas é o papel que a criança poderá assumir de transformador criativo da realidade em que vive, pois, a prática filosófica leva as crianças a compreenderem suas ações e a refletirem sobre a capacidade de pensar por si mesma.

Por fim, destaca-se a oportunidade identificada na proposta de Mendonça e Carvalho (2019), que expõe de forma contundente a relevância de se bem formular as perguntas nas comunidades de investigação, já que tais perguntas não são somente recursos educacionais, vão muito além de um mero passo metodológico dentro das sessões do programa $\mathrm{FpC}$, representando, na verdade, a parte central do pensamento e investigação. Nesse sentido, quando o professor priva a criança de criar, discutir e avaliar suas próprias perguntas, deixa de ser honrada uma das atribuições da Filosofia: 0 pensamento. Dessa forma, ao trabalhar com o programa de $\mathrm{FpC}$, o professor precisa estar ciente da necessidade de estimular as crianças a conectarem-se com as perguntas realizadas, a fim de promover uma discussão filosófica e não o conhecimento comum.

\subsection{QP2 - Quais os principais desafios relatados nestes estudos?}

Em referência aos principais desafios de pesquisas na área, pode-se apontar, como a mais recorrente, a questão da figura do professor e de como ele está preparado para aplicar o programa de FpC. De acordo com Kilby (2019), na literatura ainda não existe uma imagem completa sobre como os professores atuam nas comunidades de investigação. Canuto (2018) reforça que um dos desafios para a implementação do programa $\mathrm{FpC}$ nas escolas é a necessidade de formação para os professores, o que atualmente ainda não se encontra disponível. Nesse contexto, Michalik (2019) discute como o programa $\mathrm{FpC}$ representa um desafio particular para os professores, visto que tal perspectiva afeta suas práticas, as quais precisam ser modificadas e atualizadas. 
Desse modo, uma das maiores dificuldades encontradas é a necessidade de transformação no próprio aspecto do professor, o qual deve ser visto como um facilitador da aprendizagem, como abordam Moreno e Marta (2018). Segundo os autores, há grande necessidade de mudar a visão desses profissionais, que passam a ser facilitadores do processo, pois auxiliam os alunos a desenvolveremse sozinhos. Evidencia-se também a visão de Postiglione (2018), a qual pressupõe que a eficácia do modelo de aprendizagem oferecido pelo programa FpC depende de como o facilitador irá empregálo.

Em suma, os principais desafios apresentados pelas investigações analisadas referem-se à atuação dos professores, já que todo aprendizado que pode acontecer nas sessões do programa FpC depende de como os educadores irão abordá-la, bem como quais métodos e reflexões serão promovidos com seus alunos. Assim, ressalta-se ainda mais o papel desse profissional tão fundamental em qualquer discussão acerca de ensino ou aprendizagem.

\section{CONSIDERAÇÕES FINAIS}

A Filosofia para Criança é um programa curricular que procura desenvolver o raciocínio lógico e o pensamento reflexivo em crianças, como também procura possibilitar a prática da filosofia na tentativa de tornar a história da filosofia compreensível as crianças. Segundo, Carvalho e Santos (2020, p. 158), embora se estabeleça em espaço escolas a FpC, é muito mais que apenas um programa ou um currículo pedagógico, ao dirigir acima de tudo a seres humanos que, "pensando e agindo, se realizam ao fundamentarem as suas ideias e decisões, a filosofia apresenta-se como um espaço de diálogo sobre o mundo e sobre aquilo que, no mundo, interessa". Neste âmbito, o objetivo desta investigação foi apresentar uma revisão sistemática da literatura, focada no contexto da Filosofia para Crianças no Ensino Fundamental anos iniciais, com o intuito de expor os principais avanços e desafios recentemente atingidos nesta área.

Como resultado, foram identificados os principais avanços apresentados nos últimos anos na pesquisa sobre o programa FpC, os quais são: (1) importância da formação das comunidades de investigação; (2) relevância de ensinar-se Filosofia desde os primeiros anos de escolarização, com o intuito de desenvolver o pensamento lógico e reflexivo; (3) a elaboração eficiente das perguntas para as comunidades de investigação, resultando em estimular as crianças a participarem ativamente destes momentos.

Os principais desafios encontrados nas investigações referem-se sobretudo à figura do professor e os obstáculos enfrentados por ele na aplicação do programa de $\mathrm{FpC}$, uma vez que todo o processo de desenvolvimento dessa proposta pedagógica depende de como o professor lida com ela. Nesse sentido, destacam-se as mais relevantes dificuldades: (1) falta de literatura sobre como deve ser a atuação dos professores nas comunidades de investigação; (2) necessidade de formação específica para os professores; (3) relevância da interpretação de que os professores são facilitadores do processo de aprendizagem.

Uma das principais limitações desta pesquisa foi a pequena quantidade de bases de dados que indexam artigos na área da $\mathrm{FpC}$, proporcionando uma pequena diversidade de estudos retornados na pesquisa. Todavia, mesmo apresentando uma pequena quantidade de publicações selecionadas, a partir dessa revisão foi possível apresentar o contexto da investigação atual (2018-2020) na FpC, proporcionando uma visão sobre os aspectos positivos na adoção deste programa no Ensino 
Fundamental anos iniciais e também na Educação Infantil, elencando os avanços e os principais resultados alcançados pelos pesquisadores da área. Além disso, foram listados os principais desafios na adoção da $\mathrm{FpC}$, fato que pode incentivar o desenvolvimento de pesquisas que superem tais desafios e tragam melhores resultados e progressos para este contexto, que ainda é pouco explorado.

Finalizando, na literatura existe uma escassez muito grande de revisões sistemáticas na área do programa $\mathrm{FpC}$, o que representa uma perda significativa de conhecimento, pois uma revisão sistemática é um processo metodológico muito preciso, que gera um aporte teórico para o desenvolvimento de novas investigações e apresenta novas oportunidades de estudos. Dessarte, este estudo procurou, por meio da metodologia da revisão sistemática de literatura, identificar quais são os avanços e os desafios atuais nessa área que se apresenta tão valiosa para a formação desde os primeiros anos da educação.

\section{REFERÊNCIAS}

RODRIGUEZ, Adolfo Agundez. Programa de filosofía para niños como propuesta de educación moral: análisis comparado con otros enfoques de la educación moral. Childhood \& Philosophy, Rio de Janeiro, v.14, n. 31, p. 671-695, set./dez. 2018.

ALBERT, Sonia París. Putting philosophy to the service of schools to give children's voices real value. Childhood \& Philosophy, Rio de Janeiro, v. 14, n. 30, p. 453-470, mai./ago. 2018.

ASLANIMEHR, Parmis; MARSAL, Eva; WEBER, Barbara; KNAPP, Fabian. Nature gives and nature takes: a qualitative comparison between canadian and german children about their concepts of 'nature'. Childhood \& Philosophy, Rio de Janeiro, v. 14, n. 30, p. 483-515, mai./ago. 2018.

ALT, Katrin. Philosophising with young children as a language-promoting principle. Childhood \& Philosophy, Rio de Janeiro, v. 15, p. 01 - 20, maio 2019.

BARRIENTOS-RASTROJO, José. La filosofía con niños como experiencia transformadora. Una propuesta en organizaciones sin ánimo de lucro. Childhood \& Philosophy, Rio de Janeiro, v. 15, p. $01-28$, jun. 2019.

CANUTO, Abigail Thea. Developing children's reasoning and inquiry, concept analysis, and meaningmaking skills through the community of inquiry. Childhood \& Philosophy, Rio de Janeiro, v. 14, n. 30, p. 427-452, mai./ago. 2018.

CANTALICE, Gizolene de Fátima Barbosa da Silva; CIRINO, Maria Reilta Dantas. Considerações sobre o conceito de "experiência" presente nas teorias filosofia para/com crianças. Revista SulAmericana de Filosofia e Educação - Resafe, n. 32/33, p. 61-77, nov.2019/out.2020.

CARVALHO, Magda Costa. Filosofia para crianças: a (im)possibilidade de lhe chamar outras coisas. Rio de Janeiro: NEFI, 2020.

CARVALHO, Magda; SANTOS, Ana Isabel. O "porque" traz coisas especiais e dá perguntas. In: CARVALHO, Magda Costa. Filosofia para crianças: a (im)possibilidade de lhe chamar outras coisas. NEFI: Rio de Janeiro, 2020, p. 157-161.

CHARABATI, Esther. Peter Pan: el líder y sus seguidores. una experiencia de filosofía con niños. Childhood \& Philosophy, Rio de Janeiro, v. 15, p. 01 - 24, jun. 2019. 
DENYER, D.; TRANFIELD, D. Producing a systematic review. In: BUCHANAN, D. A.; BRYMAN, A. (Ed.). The SAGE handbook of organizational research methods. London, SAGE, p. 671-689, 2009.

DANIEL, Marie-France. Grounded theory. A research method for advancing the comprehension of philosophy for children's processes. Childhood \& Philosophy, Rio de Janeiro, v. 14, n. 29, p. 307328, jan./abr. 2018.

ELICOR, Peter Paul. Philosophical inquiry with indigenous children: an attemptto integrate indigenous forms of knowledge in philosophyfor/with children. Childhood \& Philosophy, Rio de Janeiro, v. 15, p. 01 - 22, jun. 2019.

HAWKEN, Johanna. Philosophical discussions with children: an opportunity for experiencing openmindedness. Childhood \& Philosophy, Rio de Janeiro, v. 15, p. 01 - 20, jun. 2019.

KILBY, Ben. Why teachers' beliefs and values are important in p4c research: an australian perspective. Childhood \& Philosophy, Rio de Janeiro, v. 15, p. 1-19, dez. 2019.

KAŹMIERCZAK, Monika. What is communication? Investigations with kindergarten children. Interdisciplinary Contexts of Special Pedagogy, v. 30, n. 1, p. 90-107, set. 2020.

LIPMAN, Matthew. A filosofia vai à escola. Summus, São Paulo: 1990.

LIPMAN, Matthew; SHARP, Ann Margaret; OSCANYAN, Frederick S. (Orgs). A Filosofia na sala de aula. São Paulo: Nova Alexandria, 2001.

MARISCAL, Sara Vega. Educación para la paz y razón inclusiva. El pensamiento crítico en la filosofía para niños. Innovación educativa (México, DF), v. 18, n. 78, p. 55-71, Septiembre/Diciembre, 2018.

MENDONÇA, Dina; CARVALHO, Magda Costa. The richness of questions in philosophy for children. Childhood \& Philosophy, Rio de Janeiro, v. 15, p. 01 - 21, jun. 2019.

MICHALIK, Kerstin. Teacher and learner perspectives on philosophical discussion - uncertainty as a challenge and opportunity. Childhood \& Philosophy, Rio de Janeiro, v. 15, p. 01 - 20, jun. 2019.

MORENO, Artidiello; MARTA, Mabel. Filosofía para Niños y Niñas (FPNN): una oportunidad diferente para pensar en la escuela. Ciencia y Sociedad, Santo Domingo, v. 43, n. 3, p. 25-38, 2018.

MORIYÓN, Félix Garcia. A normative approach to philosophy for children. Childhood \& Philosophy, Rio de Janeiro, v. 15, p. 01 - 12, nov. 2019.

MURRIS, Karin. Philosophy with Picturebooks. In: M. A. Peters (ed.), Encyclopedia of Educational Philosophy and Theory. Singapore: Springer, 2016.

NEWBY, Alex; GARDNER, Susan T. Meeting youngsters where they "are at": demonstrating its advantages. Childhood \& Philosophy, Rio de Janeiro, v. 15, p. 01-26, dez. 2019.

NISHIYAMA, Kei. Rethinking consensus in the community of philosophical inquiry: a research agenda. Childhood \& Philosophy, Rio de Janeiro, v. 15, p. 01-18, jun. 2019.

PAPATHANASIOU, Maria. Parents' philosophical community: when parents go to school! Childhood \& Philosophy, Rio de Janeiro, v. 15, p. 01-28, out. 2019. 
POSTIGLIONE, Enrico. Questions and performatives - communities of inquiry as conventional contexts. Childhood \& Philosophy, Rio de Janeiro, v. 14, n. 31, p. 697-714, set./dez. 2018.

RAMOS, A.; FARIA, P. M.; FARIA, A. Revisão sistemática de literatura: contributo para a inovação na investigação em Ciências da Educação. Revista Diálogo Educ., Curitiba, v. 14, n. 41, p. 1736, 2014.

REYNOLDS, Rose-Anne. Making a circle: building a community of philosophical enquiry in a postapartheid, government school in south Africa. Childhood \& Philosophy, Rio de Janeiro, v. 15, p. 01 - 21, jun. 2019.

SANTI, Marina. Collaborative problem-solving and citizenship education: a philosophical escape in the age of competencies. Childhood \& Philosophy, Rio de Janeiro, v. 15, p. 01 - 19, jun. 2019.

SHAPIRO, Carmina. El lugar de la deliberación en la filosofía para niños de Lipman. Childhood \& Philosophy, Rio de Janeiro, v. 15, p. 01 - 18, jun. 2019.

SPLITTER, Laurance Joseph. Identity and populism begone! The role of philosophy in healing a shattered and divided world. Childhood \& Philosophy, Rio de Janeiro, v. 15, p. 01-21, jun. 2019.

WALCZAK, Pawel. Why piaget does not philosophize? Critical discussion of gareth $b$. Mathews with the piagetan concept of cognitive development. Childhood \& Philosophy, v. 15, p. 1-25, JanuaryDecember, 2019.

WORLEY, Emma; WORLEY, Peter. Teaching critical thinking and metacognitive skills through philosophical enquiry. A practitioner's report on experiments in the classroom. Childhood \& Philosophy, Rio de Janeiro, v. 15, p. 01-34, dez. 2019.

Submissão: 02/07/2021

Aceito: 16/08/2021 